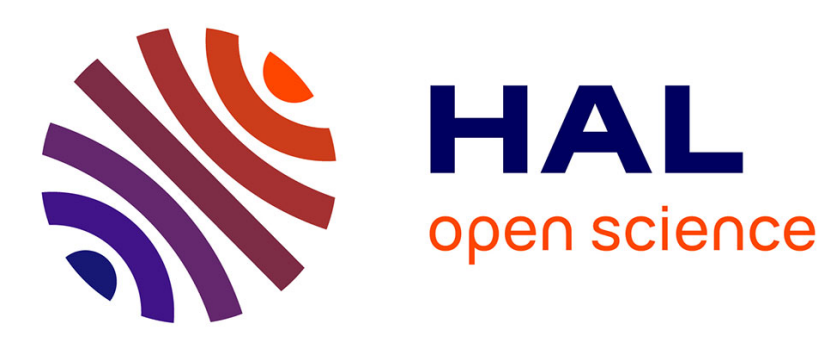

\title{
A motion-scheduled LPV control of full car vertical dynamics
}

\author{
Manh Quan Nguyen, Olivier Sename, Luc Dugard
}

\section{To cite this version:}

Manh Quan Nguyen, Olivier Sename, Luc Dugard. A motion-scheduled LPV control of full car vertical dynamics. ECC 2015 - 14th European Control Conference, Jul 2015, Linz, Austria. pp. 129 - 134. hal-01226546

\section{HAL Id: hal-01226546 \\ https://hal.science/hal-01226546}

Submitted on 16 Nov 2015

HAL is a multi-disciplinary open access archive for the deposit and dissemination of scientific research documents, whether they are published or not. The documents may come from teaching and research institutions in France or abroad, or from public or private research centers.
L'archive ouverte pluridisciplinaire HAL, est destinée au dépôt et à la diffusion de documents scientifiques de niveau recherche, publiés ou non, émanant des établissements d'enseignement et de recherche français ou étrangers, des laboratoires publics ou privés. 


\title{
A motion-scheduled LPV control of full car vertical dynamics
}

\author{
M.Q.Nguyen ${ }^{1 *}$, O.Sename ${ }^{1}$, L.Dugard ${ }^{1}$
}

\begin{abstract}
In this paper, we present a motion-scheduled $\mathrm{LPV} / H_{\infty}$ suspension controller that takes into account the three main motions of the vehicle vertical dynamics: bounce, roll and pitch motions. The new approach aims, by using a motion detection method, at designing a controller which is able to adapt the suspension forces at the four corners of the vehicle, in order to mitigate the road-induced effects. The motion detection strategy is based on the supervison of load transfer distributions (pitch and roll motions). The main idea of the LPV control is to use three scheduling parameters, representative of the motion distribution of the car dynamics, in order to adapt and distribute efficiently the suspension actuators. A full 7 degree of freedom (DOF) vertical model is used to describe the body motion (chassis and wheels) and to synthesize the LPV controller. The controller solution, derived in the $\mathrm{LPV} / H_{\infty}$ framework, is based on the LMI solution for polytopic systems. Some simulation results are presented that show the effectiveness of this approach.
\end{abstract}

Keywords: Vehicle dynamics, $L P V / H_{\infty}$ control, suspension control, motion detection, load transfer distribution.

\section{INTRODUCTION}

Automotive vehicles are extremely complex systems composed of many subsytems that, in particular enhance the driving comfort, stability and safety thanks to either passive (seat belt...) or active solutions using various actuators (ESC- electronic stability control, ABS- anti-lock braking system, controlled suspensions...). Together with many recent breakthroughs in the automotive industry, many studies have been fulfilled on either the suspension control aspects or the steering-braking control strategies, or a combination of them. (e.g. see [1], [2])

The suspension systems play a key role in vehicle dynamics. Indeed, a well designed suspension system may considerably improve not only the passenger comfort but also the car road holding. Several control design problems for suspension systems have then been tackled with many approaches during the last decades. In [3],[4] the authors presented several control strategies for semi-active suspensions (based on the Skyhook, Groundhook, ADD and LPV approaches). Other works concerning quarter car model have dealt with optimal control [5], adaptive control [6] or robust linear control [7]. Suspension control problems have also been solved on a half car models using an optimal control [8], or multi-objective control [9] or decoupling strategies [10]. Finally a full car

\footnotetext{
1 Univ. Grenoble Alpes, GIPSA-lab, F-38000 Grenoble, France CNRS, GIPSA-lab, F-38000 Grenoble, France. $\quad\{$ manh-quan.nguyen, olivier.sename, luc.dugard\}@gipsa-lab.grenoble-inp.fr

* This work was supported by the French national project INOVE / ANR 2010 BLAN 0308.
}

vertical model was considered to simultaneously handle the bounce, pitch and roll motions, using a mixed $H_{2} / H_{\infty}$ multiobjective control [11], or developing $H_{\infty}$ controllers for two decoupled vehicle heave-pitch and roll-warp subsystems [12] .

Moreover, the vehicle motion depends considerably on the road conditions and it is well admitted that the vehicle dynamics (in terms of comfort and road holding) will benefit from the online adaptation of the suspension performances. Let us mention also the "Magic Body Control" system [13] of Mercedes which achieves such an adaptation using online camera-based measurements of road profile. Some studies have been developed to adapt the suspension actuators according to the road environments (see [14] and [15]) based only on existing usual sensors (accelerometers, gyrometers). Recently, a motion mode energy method was developped by calculating the energy contribution of each vibration mode to the entire vehicle vibration. It is used to design a switched control that handles the bounce, roll and pitch motions in [16]. However, it can lead to abrupt changes and the stability is not proved.

In the present work, a new simple (and easy to implement) way to detect the vehicle motions is proposed, which uses the online computation of the load transfer distribution.

More specifically, the main contribution of this paper is to propose for the first time a motion-scheduled MultiInput Multi-Output (MIMO) LPV controller to enhance the car vertical dynamics using suspension actuators only. The MIMO suspension control strategy is designed in the LPV framework in order to allow for real time performance adaptation according to the vehicle dynamics. Indeed, by using a suitable definition of varying parameters, the controller admits a smooth transition from a motion-mode to another. Since the passengers' comfort is the main objective in this work, the aim is to improve the road induced vibration insulation on the bounce, roll and pitch motions. Thanks to $\mathrm{LPV} / H_{\infty}$ framework, the suspension controller ensures the stability and performances of the closed system for all parameter variations.

The paper is organized as follows. Section II is devoted to a brief description of the full vehicle model used for synthesis and validation. Section III presents the method allowing to detect the different motions of vehicle. Section IV describes the design of a LPV/ $H_{\infty}$ suspension controller that will adapt to the three motions of chassis. In section $\mathrm{V}$, the results of the proposed method are given along with some time domain simulations. Finally, some conclusions are drawn in the last section.

Throughout the paper, the following notations will be 
adopted: subscripts $i=(f, r)$ and $j=(l, r)$ are used to identify the vehicle front, rear and left, right positions respectively. The subscripts $(s, t)$ stand for the forces provided by suspensions and tires, respectively. The index $(x, y, z)$ denotes forces or dynamics in the longitudinal, lateral and vertical axes, respectively. $z_{d e f_{i j}}$ holds for the suspension deflection at each corner of the vehicle. $m=m_{s}+m_{u s_{f l}}+m_{u s_{f r}}+m_{u s_{r l}}+m_{u s_{r r}}$ is the total vehicle mass.

\section{VEHICLE MODELING}

In this work, a full car vertical model is used for the analysis and control of the vehicle dynamic behaviors. This is a 7 degree of freedom (DOF) suspension model, obtained from a nonlinear full vehicle model (referred in [2],[17], [18]). The corresponding parameters are given in the table I. This model not only involves the chassis dynamics ( vertical $\left(z_{s}\right)$, roll $(\theta)$ and pitch $\left.(\phi)\right)$, but it also figures out the vertical displacements of the wheels $\left(z_{u s_{i j}}\right)$. The dynamic equations of this 7 DOF model are given as follows:

$$
\left\{\begin{array}{l}
m_{s} \ddot{z}_{s}=-F_{s f l}-F_{s f r}-F_{s r l}-F_{s r r}+F_{d z} \\
I_{x} \ddot{\theta}=\left(-F_{s f r}+F_{s f l}\right) t_{f}+\left(-F_{s r r}+F_{s r l}\right) t_{r}+m h a_{y}+M_{d x} \\
I_{y} \ddot{\phi}=\left(F_{s r r}+F_{s r l}\right) l_{r}-\left(F_{s f r}+F_{s f l}\right) l_{f}-m h a_{x}+M_{d y} \\
m_{u s} \ddot{z}_{u s_{i j}}=-F_{s_{i j}}+F_{t z_{i j}}
\end{array}\right.
$$

where $I_{x}$ (resp. $I_{y}$ ) is the moment of inertia of the sprung mass around the longitudinal (resp. lateral) axis, $h$ : the height of center of gravity (COG), $z_{s}$ the vertical displacement of COG, $\theta$ the roll angle of the sprung mass, $\phi$ the pitch angle of the sprung mass, $z_{u s_{i j}}$ the vertical displacements of wheels, $a_{x}, a_{y}$ denote the $\mathrm{x}$ - and y-directional accelerations of the chassis, $F_{d z}$ is the vertical force disturbance; $M_{d x}, M_{d y}$ are the disturbance moments along the $\mathrm{x}, \mathrm{y}$-axis respecitively). $F_{t z_{i j}}$ are the vertical tire forces, given as:

$$
F_{t z_{i j}}=-k_{t_{i j}}\left(z_{u s_{i j}}-z_{r_{i j}}\right)
$$

where $k_{t_{i j}}$ : the stiffness coefficient of the tires.

Suspension model: The vertical suspension forces $F_{s_{i j}}$ at the 4 corners of the vehicle are modeled by a spring and a damper (see [19]) with non linear characteristics for simulation and linear ones for control design. The equation (3) allows to model the suspension force used in the control design step:

$$
F_{s_{i j}}=k_{i j}\left(z_{s_{i j}}-z_{u s_{i j}}\right)+c_{i j}\left(\dot{z}_{s_{i j}}-\dot{z}_{u s_{i j}}\right)+u_{i j}^{H_{\infty}}
$$

where $k_{i j}$ is the nominal spring stiffness coefficient, $z_{s_{i j}}$ is the chasis position at each corner, $c_{i j}$ the nominal damping coefficient and $u_{i j}^{H_{\infty}}$ the suspension control $\left(u_{i j}^{H_{\infty}}=0\right.$ holds for passive suspension).

By substituting the tire force equations (2) and the suspension force equations (3) into the vehicle equations (1) and assuming that the roll and pitch angles are small enough, the state-space representation of the dynamical equation (1) is given by ([20]):

$$
\dot{x}(t)=A x(t)+B_{1} w(t)+B_{2} u
$$

where:

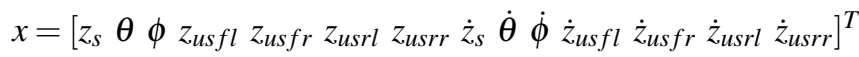
is the state vector of the full car model.

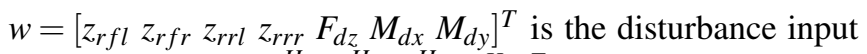
vector, and $u=\left[u_{f l}^{H_{\infty}}, u_{f r}^{H_{\infty}}, u_{r l}^{H_{\infty}}, u_{r r}^{H_{\infty}}\right]^{T}$ is the control input vector.

$$
\begin{aligned}
& \text { and } A=\left(\begin{array}{cc}
0_{7 \times 7} & I_{7 \times 7} \\
-M_{z}^{-1} K_{z} & -M_{z}^{-1} B_{z}
\end{array}\right) ; B_{2}=\left(\begin{array}{c}
0_{7 \times 4} \\
M_{z}^{-1} T_{a}
\end{array}\right) \text {; } \\
& B_{1}=\left(\begin{array}{cc}
0_{7 \times 4} & 0_{7 \times 3} \\
M_{z}^{-1} K_{r} & I_{7 \times 3}
\end{array}\right) ; M_{z}=\left(\begin{array}{cc}
M_{s} & 0_{3 \times 4} \\
0_{4 \times 3} & M_{u}
\end{array}\right) \text {; } \\
& B_{z}=\left(\begin{array}{cc}
T B_{s} T^{T} & -T B_{s} \\
-B_{s} T^{T} & B_{s}
\end{array}\right) ; K_{z}=\left(\begin{array}{cc}
T K_{s} T^{T} & -T K_{s} \\
-K_{s} T^{T} & K_{s}+K_{t}
\end{array}\right) ; \\
& K_{r}=\left(\begin{array}{c}
0_{3 \times 4} \\
K_{t}
\end{array}\right) ; T_{a}=\left(\begin{array}{c}
T \\
-I_{4 \times 4}
\end{array}\right) \text {; } \\
& M_{s}=\operatorname{diag}\left[m_{s}, I_{x}, I_{y}\right] ; M_{u}=\operatorname{diag}\left[m_{u s f l}, m_{u s f r}, m_{u s r l}, m_{u s r r}\right] ; \\
& B_{s}=\operatorname{diag}\left[c_{f l}, c_{f r}, c_{r l}, c_{r r}\right] ; K_{s}=\operatorname{diag}\left[k_{s f l}, k_{s f r}, k_{s r l}, k_{s r r}\right] \text {; } \\
& K_{t}=\operatorname{diag}\left[k_{t f l}, k_{t f r}, k_{t r l}, k_{t r r}\right] ; T=\left[\begin{array}{cccc}
1 & 1 & 1 & 1 \\
t_{f} & -t_{f} & t_{r} & -t_{r} \\
-l_{f} & -l_{f} & l_{r} & l_{r}
\end{array}\right] ;
\end{aligned}
$$

Remark: The manipulations to obtain the state state representation of the $7 \mathrm{DOF}$ vertical model of the vehicle is omitted here. The interested reader can refer to [21], [20] for more details.

In the remaining sections, this 7DOF model is used to design a LPV control with suspension actuators (see Fig.1). One uses also the "Clipped strategy" (as [3]) that insures the dissipativity caracteristic of the semi-active suspension. The "clipped method" is derived thanks to the force/deflection relation shown in Fig. 2. The principle is simple: for a given deflection speed $\left(\dot{z}_{d e f}\right)$, if the controller gives a force $F^{*}$ out of the achivable force area, the force provided to the system will be the projection $F^{\perp}$ of $F^{*}$ on the admissible force range, ensuring the semi-activeness property. This method will be integrated in the simulation.

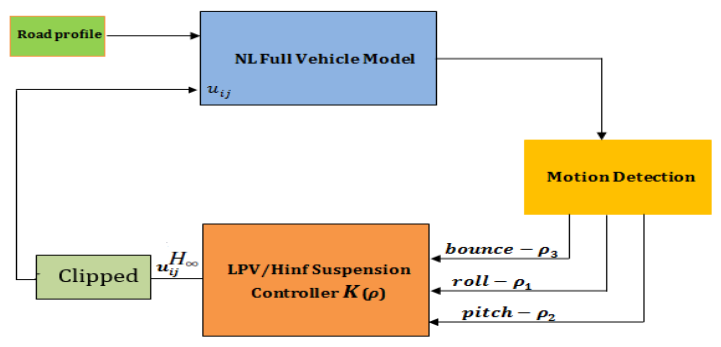

Fig. 1. Suspension control plant using motion detect

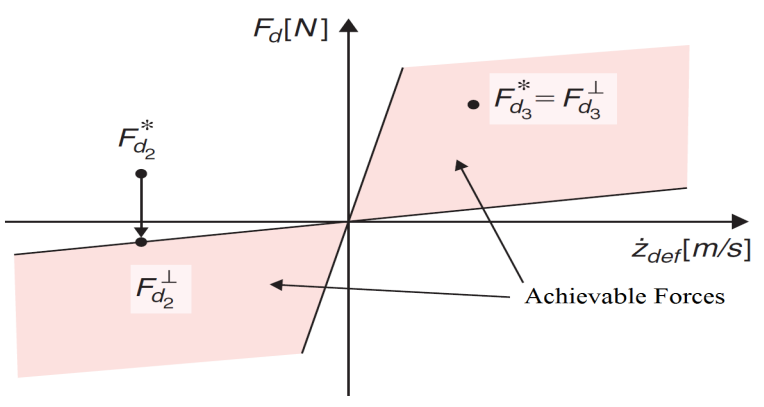

Fig. 2. Clipped approach principe 


\begin{tabular}{lccl}
\hline Symbol & Value & Unit & Signification \\
\hline \hline$m_{s}$ & 350 & $\mathrm{~kg}$ & suspended mass \\
$m_{u s_{f j}}$ & 35 & $\mathrm{~kg}$ & front unsprung mass \\
$m_{u s_{r j}}$ & 32.5 & $\mathrm{~kg}$ & rear unsprung mass \\
$I_{x} ; I_{y} ; I_{z}$ & $250 ; 1400 ; 2149$ & $\mathrm{~kg} \cdot \mathrm{m}^{2}$ & roll, pitch, yaw inertia \\
$I_{w}$ & 1 & $\mathrm{~kg} \cdot \mathrm{m}^{2}$ & wheel inertia \\
\hline$t_{f} ; t_{r}$ & $1.4 ; 1.4$ & $\mathrm{~m}$ & front, rear axle \\
$l_{f} ; l_{r}$ & $1.4 ; 1$ & $\mathrm{~m}$ & COG-front, rear distance \\
$R$ & 0.3 & $\mathrm{~m}$ & nominal wheel radius \\
$h$ & 0.4 & $\mathrm{~m}$ & chassis height \\
\hline$k_{f j}$ & 29500 & $\mathrm{~N} / \mathrm{m}$ & front suspension stiffness \\
$k_{r j}$ & 20000 & $\mathrm{~N} / \mathrm{m}$ & rear suspension stiffness \\
$c_{f j}$ & 1500 & $\mathrm{~N} / \mathrm{m} / \mathrm{s}$ & front suspension damping \\
$c_{r j}$ & 3000 & $\mathrm{~N} / \mathrm{m} / \mathrm{s}$ & rear suspension damping \\
$k_{t_{i j}}$ & 208000 & $\mathrm{~N} / \mathrm{m}$ & tire stiffness \\
$c_{t_{i j}}$ & 10 & $\mathrm{~N} / \mathrm{m} / \mathrm{s}$ & tire damping \\
\hline$b_{t}$ & 8.3278 & - & lateral tire parameter \\
$c_{t}$ & 1.1009 & - & lateral tire parameter \\
$d_{t}$ & 2268 & - & lateral tire parameter \\
$e_{t}$ & -1.1661 & - & lateral tire parameter \\
$g$ & 9.81 & $\mathrm{~m} / \mathrm{s}^{2}$ & gravitational constant \\
\hline
\end{tabular}

TABLE I

Renault MÉgane Coupé Parameters

\section{VEHICLE MOTION DETECTION}

The study of vehicle dynamics is complex since it requires to account for translation (lateral, longitudinal, vertical) and rotation (roll, pitch, yaw) modes. As emphasized in many works, they are strongly coupled even if the vehicle dynamics are often decomposed to solve some local problems (braking control, steering control...).

This paper is concerned with the improvement of the vertical dynamics that include vertical, pitch, and roll motions. More particularly, as considered in previous studies ([11],[12],[16],[22]...) the objective is to develop a suspension control strategy that aims at reducing the effect of the road induced vibrations, and thus to enhance the passengers' comfort. Note that the road holding objective could be considered as well since the 7 DOF model accounts for the wheel position dynamics (this could be the scope of future works). Moreover, as stated in the introduction, the vibration insulation for the vertical, roll and pitch motions will be based on a motion detection strategy by using the estimation of some load transfers.

Motions supervision based on load transfers: This method consists in calculating the load transfer distributions as represented in Fig.3:

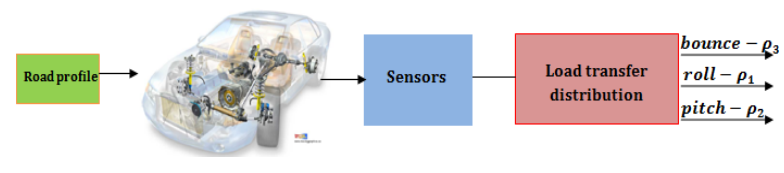

Fig. 3. Motion detection using load transfer distribution

\section{Roll monitoring by lateral load transfer $\left(\rho_{1}\right)$ :}

The main idea is based on the evaluation the lateral load transfer when the vehicle is running (see [23]). As soon as there exists a load transfer from the left to the right or vice-versa, it means that the vehicle is faced with roll vibrations. Computing the right and left vertical forces allows to define:

$$
\rho_{1}=\left|\frac{F_{z_{l}}-F_{z_{r}}}{F_{z_{l}}+F_{z_{r}}}\right|
$$

with:

$$
\left\{\begin{array}{l}
F_{z_{l}}=m_{s} \frac{g}{2}+m_{s} h \frac{a_{y}}{l_{f}} \\
F_{z_{r}}=m_{s} \frac{g}{2}-m_{s} h \frac{a_{y}}{l_{r}}
\end{array}\right.
$$

where $F_{z_{l}}$ and $F_{z_{r}}$ are the vertical forces, $a_{y}$ is the lateral acceleration. Note that $\rho_{1} \in\left[\begin{array}{ll}0 & 1\end{array}\right]$. When $\rho_{1} \rightarrow 0$, there are neither lateral load transfer, nor roll motion. When $\rho_{1} \neq 0$, the vehicle is in the roll motion.

Pitch monitoring by longitudinal load transfer $\left(\rho_{2}\right)$ :

Using the same principle as previously, the longitudinal load transfer (see [24]) is defined between the front and rear wheels when the vehicle accelerates or brakes, leading to pitch vibration. The pitch monitor is then defined as:

$$
\rho_{2}=\left|\frac{\left(F_{z_{f}} \frac{L}{l_{r}}-F_{z_{r}} \frac{L}{l_{f}}\right)}{\left(F_{z_{f}} \frac{L}{l_{r}}+F_{z_{r}} \frac{L}{l_{f}}\right)}\right|
$$

where $F_{z_{f}}, F_{z_{r}}$ are the front and rear forces, given by :

$$
\left\{\begin{array}{l}
F_{z_{f}}=m_{s}\left(\frac{l_{r}}{L} \cos (\phi)+\frac{h}{L} \sin (\phi)\right)-m_{s} a_{x} \frac{h}{L} \\
F_{z_{r}}=m_{s}\left(\frac{l_{f}}{L} \cos (\phi)-\frac{h}{L} \sin (\phi)\right)+m_{s} a_{x} \frac{h}{L}
\end{array}\right.
$$

where $a_{x}$ is the longitudinal acceleration. Note that $\rho_{2} \in\left[\begin{array}{ll}0 & 1\end{array}\right]$. In reality, when the vehicle speeds up, the load is transferred to the rear wheels, and during the braking it is transfered to the front wheels. The longitudinal load transfer distribution is handled as: whilst $\rho_{2} \rightarrow 0$, there are no longitudinal load transfer, no pitch motion. Conversely when $\rho_{2} \neq 0$, the pitch motion is detected.

Bounce monitoring $\left(\rho_{3}\right)$ :

Thanks to the two load transfer distribution monitoring system for roll and pitch motions, an another scheduling parameter $\rho_{3}$ will be used to monitor the bounce motion. This parameter is chosen as:

$$
\rho_{3}=\left|\left(1-\rho_{1}-\rho_{2}\right)\right| \text {. }
$$

By this way, $\rho_{3} \in\left[\begin{array}{ll}0 & 1\end{array}\right]$, when $\rho_{3} \neq 0$, the vertical motion $\left(z_{s}\right)$ should be taken into account.

Remark: In this load transfer distribution method, only two accelerometers are needed to measure the lateral and longitudinal accelerations, one gyrometer sensor to measure the pitch angle. Thus, it is much easier than the energy method developed in [16] (that requires much more sensors) to implement in real time .

\section{A LPV/H$H_{\infty}$ SUSPENSION CONTROLLER FOR GLOBAL CHASSIS DYNAMIC}

From the previous motion detection strategies, an $L P V / H_{\infty}$ motion-scheduled suspension control is proposed to ameliorate the vehical vertical dynamics. This controller is designed in the $H_{\infty}$ framework, which allows to get real-time adaptive performances using parameter dependent weighting functions. 


\section{A. Global control structure model}

The controller is tuned thanks to the $\mathrm{LPV} / H_{\infty}$ strategy using a full $7 \mathrm{DOF}$ vertical model. The generalized plant, given in Fig.4, includes the parameterized weighting functions. As

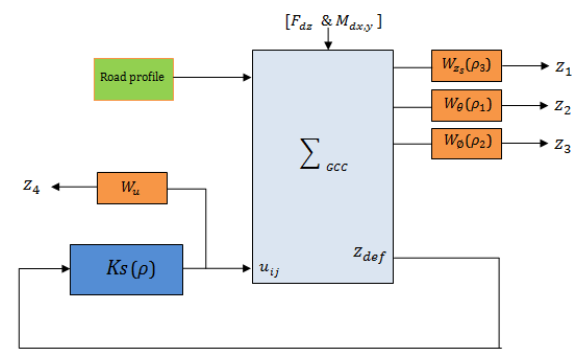

Fig. 4. Suspension generalized control plant

discussed previously, one uses the three varying parameters to schedule the weighting functions for the control objectives. These filters are selected as follows:

- $W_{z_{s}}\left(\rho_{3}\right)=\rho_{3} \frac{3}{s /\left(2 \pi f_{1}\right)+1}$ is shaped to reduce bounce amplification of the sprung mass $\left(z_{s}\right)$ between $[0,10] \mathrm{Hz}$ $\left(f_{1}=8 H z\right)$.

- $W_{\theta}\left(\rho_{1}\right)=\rho_{1} \frac{2}{s /\left(2 \pi f_{2}\right)+1}$, aims at attenuating the roll amplification in low frequency $\left(f_{2}=2 \mathrm{~Hz}\right)$.

- $W_{\phi}\left(\rho_{2}\right)=\rho_{2} \frac{2}{s /\left(2 \pi f_{3}\right)+1}$ reduces the pitch motion in particularly in low frequency $\left(f_{3}=2 \mathrm{~Hz}\right)$.

- $W_{u}=10^{-2}$ limits the control signal amplification. The coefficient is chosen according to the actuator gain.

In addition, some weighting functions, derived by $W_{z_{r i j}}=$ $3.10^{-2}$ are used to shape the road profiles $\left(z_{r i j}\right)$.

The authors stress that the interest of parameter dependant weighting functions is to allow for performance adaptation to the behavior of the vehicle dynamic. Indeed, the suspension actuators will be tuned according to the varying parameters in order to meet the desired performance. For example, as far as the roll motion is concerned, when the scheduling parameter $\rho_{1} \longrightarrow 1$, the gain of the weighting function $W_{\theta}\left(\rho_{1}\right)$ is large, and therefore the roll angle will be penalized. In the same way, when $\rho_{2}, \rho_{3}$ are large, the pitch and bounce motions will be reduced.

It is worth noting that, while the model car is a LTI system, the generalized plant (which consists of the suspension model and weighting functions) is a LPV one. Moreover, according to the interconnection between the 7 DOF vertical model $\Sigma_{\text {vert }}$ and the weighting functions defined above, the following parameter dependent suspension generalized plant $\left(\Sigma_{g v}(\rho)\right)$ is obtained:

$$
\Sigma_{g v}(\rho):\left\{\begin{array}{l}
\dot{\xi}=A(\rho) \xi+B_{1}(\rho) \tilde{w}+B_{2} u \\
\tilde{z}=C_{1}(\rho) \xi+D_{11}(\rho) \tilde{w}+D_{12} u \\
y=C_{2} \xi+D_{21} \tilde{w}
\end{array}\right.
$$

where $\xi=\left[\begin{array}{ll}\chi_{v e r t} & \chi_{w f}\end{array}\right]^{T}, \chi_{v e r t}, \chi_{w f}$ are the vertical model and weighting function states respectively.

$\tilde{z}=\left[\begin{array}{llll}z_{1} & z_{2} & z_{3} & z_{4}\end{array}\right]^{T}$ are the controlled outputs,

$\tilde{w}=\left[\begin{array}{lll}z_{r_{i j}} & F_{d z} & M_{d x, y}\end{array}\right]$ : the disturbance input signals,

$y=z_{d e f_{i j}} ; u=\left[u_{f l}^{H_{\infty}}, u_{f r}^{H_{\infty}}, u_{r l}^{H_{\infty}}, u_{r r}^{H_{\infty}}\right]^{T}$ : the suspension control signals,

$\rho=\left[\begin{array}{lll}\rho_{1} & \rho_{2} & \rho_{3}\end{array}\right]:$ the varying parameters, $\rho_{i} \in[01], i=1,2,3$.

The generalized plant (10) depends on 3 varying parameters $\left(\rho_{1}, \rho_{2}, \rho_{3}\right)$, so $\Sigma_{g v}(\rho)$ can be expressed as a polytopic system composed by $N=2^{3}$ vertices $\omega_{i}, \mathrm{i}=1, \ldots, 8$ :

$$
\Sigma_{g v}(\rho)=\Sigma_{i=1}^{N=2^{3}} \alpha_{i}(\rho) \Sigma_{g v}^{i}(\rho)
$$

where $\quad \alpha_{i}(\rho):=\frac{\Pi_{k=1}^{3}\left|\rho_{k}-C\left(\omega_{i}\right)_{k}\right|}{\Pi_{k=1}^{3}\left(\overline{\rho_{k}}-\underline{\rho_{k}}\right)}, i=1, \ldots, 8$ and $\sum_{i=1}^{8} \alpha_{i}(\rho)=1 ; \rho_{k} \in\left[\begin{array}{ll}\rho_{k} & \overline{\rho_{k}}\end{array}\right]$.

$\Sigma_{g v}^{i}(\rho)$ defines the system at $i^{\text {th }}$ vertice;

$C\left(\omega_{i}\right)_{k}:=\left\{\overline{\rho_{k}}\right.$ if $\left(\omega_{i}\right)_{k}=\underline{\rho_{k}}$ or $\underline{\rho_{k}}$ if $\left.\left(\omega_{i}\right)_{k}=\overline{\rho_{k}}\right\}$.

It is important to note that the suspension controller is designed using a LPV strategy for the polytopic system.

\section{B. $L P V / H_{\infty}$ polytopic solution}

The $\mathrm{LPV} / H_{\infty}$ problem (see [25] ) consists in finding a stabilizing controller, scheduled by $\rho$, of the form:

$$
K_{c}(\rho):\left\{\begin{array}{l}
\dot{x_{c}}=A_{c}(\rho) x_{c}+B_{c}(\rho) y \\
u_{i j}^{H_{\infty}}=C_{c}(\rho) x_{c}
\end{array}\right.
$$

that minimizes the $H_{\infty}$ norm of transfer function between the input disturbances $\tilde{w}$ and controlled outputs $\tilde{z}$. The synthesis of such a controller can be made in the framework of $\mathrm{LPV} / \mathrm{H}_{\infty}$ based on the LMI solution (see [26],[27]) for polytopic systems (here in the framework of quadratic stabilization).

Let us note that the generalized plant (10) has no direct transfer between the input and the output (i.e $D_{22}=0$ ). Moreover, the input and output matrices $\left[B_{2}, D_{12}\right],\left[C_{2}, D_{21}\right]$ do not depend on parameters $\rho=\left[\rho_{1}, \rho_{2}, \rho_{3}\right]$. Then, the polytopic system is a convex combination (as (11)) of the systems defined at each vertex of a polytope given by the bounds of the scheduling parameters. The designed controller is also the convex combination of the 8 controllers synthesized at the 8 vertices of the polytope. Thanks to the polytopic approach, the global suspension controller can ensure the global stability because each of the controllers at a vertex is quadratically stable.

The main contribution in this synthesis is that the controller can adapt to vehicle vibrations. This also allows a smooth transition from a motion to another, and ensures the closed loop stability for all parameter variations. Moreover, when $\rho_{i} \neq 0, i=1,2,3$, the designed controller provides an accurate suspension force to warrant the vehicle stability and driving comfort.

\section{SIMULATION RESULTS}

To validate the proposed controller strategy, simulations are performed on a full non linear vehicle model [2] that includes non linear suspension forces and numerical values in the Table I based on a Renault Mégane Coupé.

The following scenario (see Fig.5, Fig.6) is used to test the effectiveness of the proposed $\mathrm{LPV} / \mathrm{H}_{\infty}$ :

- the vehicle runs at $45 \mathrm{~km} / h$ in a straight line on dry road ( $\mu=1$, where $\mu$ stands for the adherence to the road). 
- A $5 \mathrm{~cm}$ bump occurs simultaneously on the left and right wheels (from $t=0.5 \mathrm{~s}$ to $t=1 \mathrm{~s}$ ) to excite the bounce motion.

- The vehicle accelerates from $t=3 \mathrm{~s}$ to $t=3.5 \mathrm{~s}$, which induces a pitch motion.

- A double lines change is performed from $t=2 s$ to $t=$ $6 s)$.

- And a $5 \mathrm{~cm}$ bump on the left wheels (from $t=5 \mathrm{~s}$ to $t=5.5 s$ ) during the manoeuvre that causes the roll vibration.

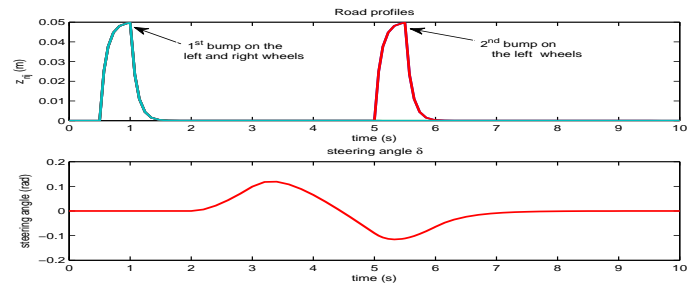

Fig. 5. Input signals

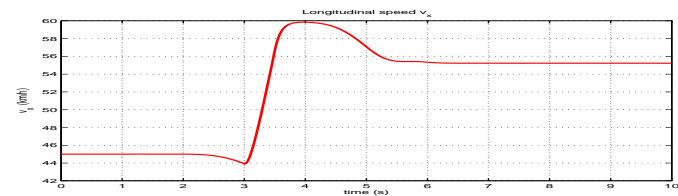

Fig. 6. Longitudinal Speed

Time domain analysis:

The results of the simulation using the load transfer method to detect the vehicle motions are given below. Fig.7
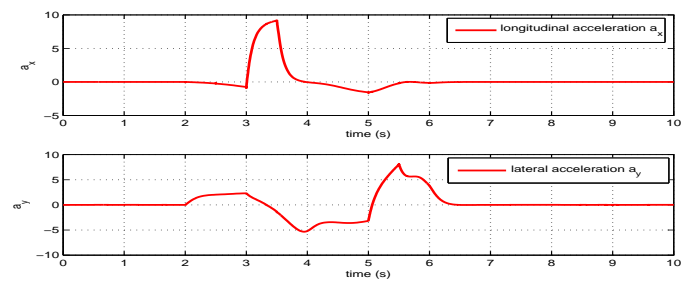

Fig. 7. Longitudinal and lateral accelerations of vehicle

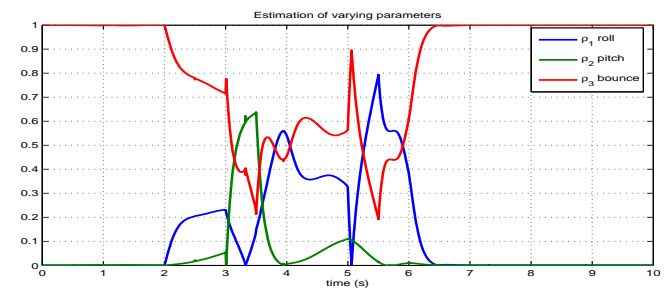

Fig. 8. Scheduling parameters

shows the longtidunal and lateral accelerations which induce the pitch and roll motions of the vehicle. The longitudinal acceleration from $t=3-3.5 \mathrm{~s}$ is positive since the vehicle accelerated. During the manoeuvre $(t=2-6 s)$ and when a bump occurs on the left wheels $(t=5-5.5 s)$, the vehicle has a non zero lateral acceleration.

Fig.8 shows the scheduling parameters for the LPV controller. We see that, at the beginning, the LPV controller concentrates on improving the bounce motion $\left(\rho_{1} \longrightarrow 1\right)$. From $t=3-3.5 s$, the vehicle accelerates, the scheduling parameter of pitch motion $\rho_{2}$ increases, the pitch motion is mitigated. In the same way, when the bump occurs on left wheels $(t=5-5.5 s)$, the varying parameter of roll motion $\rho_{2}$ allows to tune suspension actuators to reduce this vibration. Fig.9, Fig. 10 and Fig.11 illustrate the three main

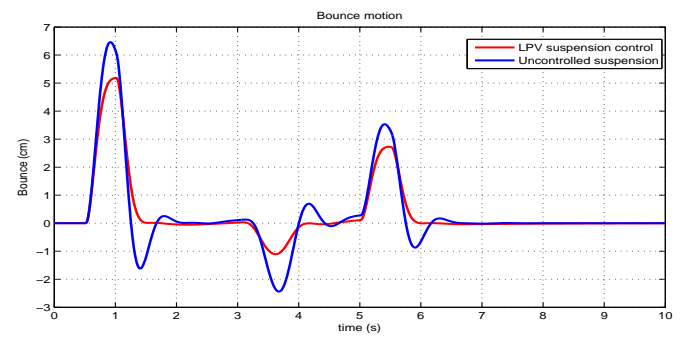

Fig. 9. Bounce motion

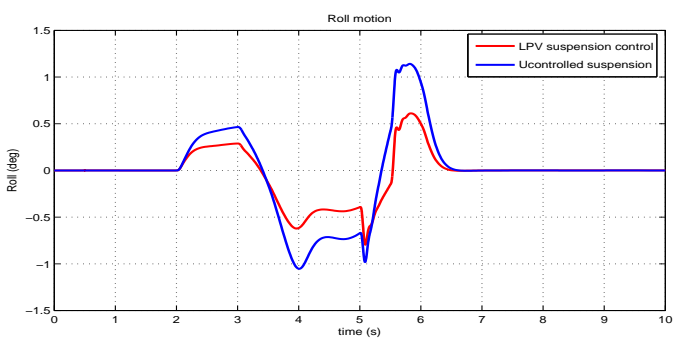

Fig. 10. Roll motion

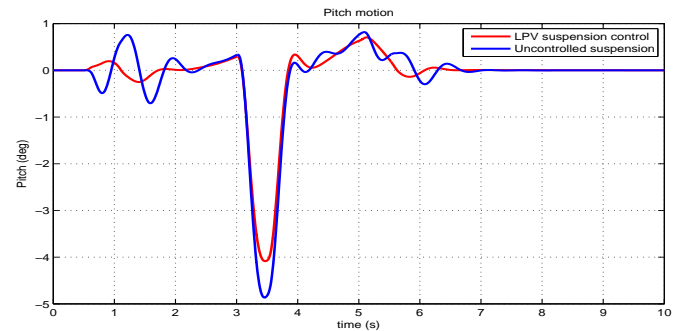

Fig. 11. Pitch motion

motions: bounce, roll and pitch respectively of the vehicle in the controlled suspensions case and compared to the uncontrolled case $\left(u_{i j}^{H_{\infty}}=0\right)$. Obviously, the LPV suspension controller gives better performance results for the vehicle since it reduces the amplification of these motions compared with the uncontrolled suspension model. Fig.12 shows the chasis acceleration of the vehicle.

In Fig.13, the input forces $F_{s i j}$ adapt the suspension actuators according to the motions of the vehicle so that the performance objectives are achieved. 


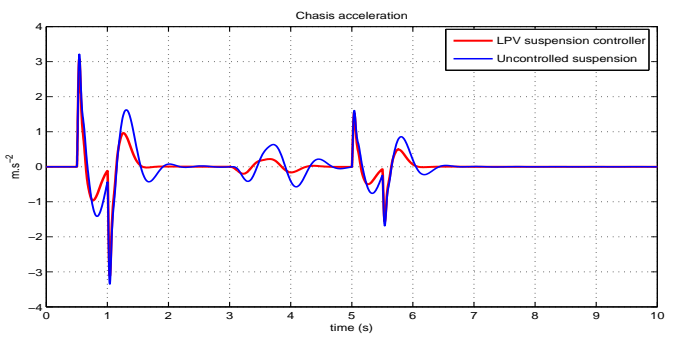

Fig. 12. Chasis acceleration

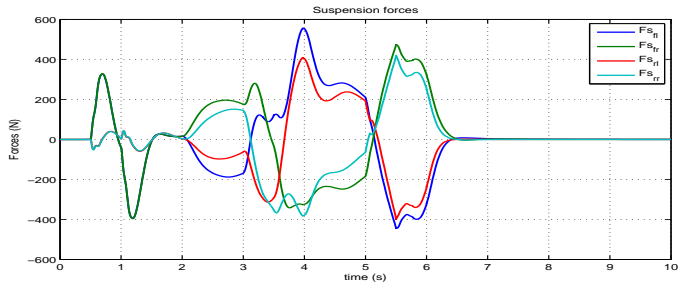

Fig. 13. Suspension forces

\section{CONCLUSIONS}

The paper presented a new MIMO LPV motion-scheduled suspension control to enhance the full car vehicle vertical dynamics. A single suspension LPV controller is designed to mitigate the vehicle vibrations and guarantee the ride quality. It is worth noting that this strategy permits to have a smooth adaptation when the vehicle has to face road changing without switching between several controllers that would be dedicated to a specific mode. The authors stress that using the LPV framework allows also to simplify the implementation procedure. The next step of this work will be the implementation of this strategy on a test benchmark, available at Gipsa-lab Grenoble, developed in collaboration with a high-tech start-up "SOBEN". It consists of a vehicle equipped with four controllable Electro-Rheological dampers, and of 4 DC motors generating separately different road profiles on each wheel. First experimental results on the test-bed are presented in [28] .

\section{REFERENCES}

[1] P. Gaspar, Z. Szabo, J. Bokor, C. Poussot-Vassal, O. Sename, L. Dugard, et al., "Toward global chassis control by integrating the brake and suspension systems," in Proceedings of the 5th IFAC Symposium on Advances in Automotive Control, AAC, California, US, August 2007.

[2] C. Poussot-Vassal, O. Sename, L. Dugard, P. Gaspar, Z. Szabo, and J. Bokor, "Attitude and handling improvements through gainscheduled suspensions and brakes control," Control Engineering Practice, vol. 19, no. 3, pp. 252-263, 2011.

[3] S. M. Savaresi, C. Poussot-Vassal, C. Spelta, O. Sename, and L. Dugard, Semi-active suspension control design for vehicles. Elsevier, 2010.

[4] C. Poussot-Vassal, C. Spelta, O. Sename, S. M. Savaresi, and L. Dugard, "Survey and performance evaluation on some automotive semi-active suspension control methods: A comparative study on a single-corner model," Annual Reviews in Control, vol. 36, no. 1, pp. 148-160, 2012.

[5] D. Hrovat, "Survey of advanced suspension developments and related optimal control applications," Automatica, vol. 33, no. 10, pp. 17811817, 1997.
[6] G. Koch and T. Kloiber, "Driving state adaptive control of an active vehicle suspension system," Control Systems Technology, IEEE Transactions on, vol. 22, no. 1, pp. 44-57, Jan 2014.

[7] C. Lauwerys, J. Swevers, and P. Sas, "Robust linear control of an active suspension on a quarter car test-rig," Control Engineering Practice, vol. 13, no. 5, pp. 577-586, 2005.

[8] R. Krtolica and D. Hrovat, "Optimal active suspension control based on a half-car model," in Decision and Control, 1990., Proceedings of the 29th IEEE Conference on. IEEE, 1990, pp. 2238-2243.

[9] P.-Y. Sun and H. Chen, "Multiobjective output-feedback suspension control on a half-car model," in Control Applications, 2003. CCA 2003. Proceedings of 2003 IEEE Conference on, vol. 1. IEEE, 2003, pp. 290-295.

[10] Y. Zhang and A. Alleyne, "A new approach to half-car active suspension control," in American Control Conference, 2003. Proceedings of the 2003, vol. 5. Colorado,US: IEEE, June 2003, pp. 3762-3767.

[11] J. Lu and M. DePoyster, "Multiobjective optimal suspension control to achieve integrated ride and handling performance," Control Systems Technology, IEEE Transactions on, vol. 10, no. 6, pp. 807-821, 2002.

[12] K. Hayakawa, K. Matsumoto, M. Yamashita, Y. Suzuki, K. Fujimori, and H. Kimura, "Robust $\mathscr{H}_{\infty}$-output feedback control of decoupled automobile active suspension systems," Automatic Control, IEEE Transactions on, vol. 44, no. 2, pp. 392-396, 1999.

[13] Mercedes, Body Magic Control. [Online]. Available: http://techcenter mercedes-benz.com/fr_FR/magic_body_control/detail.html

[14] I. Fialho and G. J. Balas, "Road adaptive active suspension design using linear parameter-varying gain-scheduling," Control Systems Technology, IEEE Transactions on, vol. 10, no. 1, pp. 43-54, 2002.

[15] J. C. Tudon-Martınez, S. Fergani, S. Varrier, O. Sename, L. Dugard, R. Morales-Menendez, and R. Ramirez-Mendoza, "Road adaptive semi-active suspension in a pick-up truck using an lpv controller," in Proceedings of IFAC AAC 2013, Tokyo, Japan, September 2013.

[16] H. Du, N. Zhang, and L. Wang, "Switched control of vehicle suspension based on motion-mode detection," Vehicle System Dynamics, vol. 52, no. 1, pp. 142-165, 2014.

[17] T. D. Gillespie, Fundamentals of vehicle dynamics, 1992

[18] U. Kiencke and L. Nielsen, "Automotive control systems: for engine, driveline, and vehicle," Measurement Science and Technology, vol. 11, no. 12 , p. $1828,2000$.

[19] A. Zin, O. Sename, P. Gaspar, L. Dugard, and J. Bokor, "Robust lpv/ $\mathscr{H}_{\infty}$ control for active suspensions with performance adaptation in view of global chassis control," Vehicle System Dynamics, vol. 46, no. 10, pp. 889-912, 2008.

[20] D. Sammier, "Sur la modélisation et la commande de suspension de véhicules automobiles," Ph.D. dissertation, Institut National Polytechnique de Grenoble-INPG, 2001.

[21] J. H. Park and Y. S. Kim, "Decentralized variable structure control for active suspensions based on a full-car model," in Control Applications, 1998. Proceedings of the 1998 IEEE International Conference on, vol. 1. IEEE, 1998, pp. 383-387.

[22] J. Wang and D. Wilson, "Multi-objective control of decoupled vehicle suspension systems," in Decision and Control, 2001. Proceedings of the 40th IEEE Conference on, vol. 1. IEEE, 2001, pp. 535-540.

[23] S. Fergani, O. Sename, and L. Dugard, "A lpv suspension control with performance adaptation to roll behavior, embedded in a global vehicle dynamic control strategy," in Control Conference (ECC), 2013 European, Zurich, Switzerland, July 2013, pp. 1487-1492.

[24] M. Short, M. J. Pont, and Q. Huang, "Simulation of vehicle longitudinal dynamics," Safety and Reliability of Distributed Embedded Systems, pp. 04-01, 2004.

[25] O. Sename, P. Gaspar, and J. Bokor, Robust Control and Linear Parameter Varying approaches: Application to Vehicle Dynamics. Spinger, 2013.

[26] P. Apkarian, P. Gahinet, and G. Becker, "Self-scheduled h control of linear parameter-varying systems: a design example," Automatica, vol. 31, no. 9, pp. 1251-1261, 1995.

[27] C. Scherer, P. Gahinet, and M. Chilali, "Multiobjective outputfeedback control via lmi optimization," Automatic Control, IEEE Transactions on, vol. 42, no. 7, pp. 896-911, 1997.

[28] O. Sename, M. Basset, B. Talon, B. D'Andrea-Novel, D. Koenig, and J. Martinez, "The inove anr 2010 blan 0308 project: Integrated approach for observation and control of vehicle dynamics," in ECC Strabourg,France, June 2014, pp. 2340-2345. 